\title{
People with Disabilities Leading the Design of Serious Games and Virtual Worlds
}

\author{
Yurgos Politis ${ }^{1}$, Nigel Robb ${ }^{2}$, Anita Yakkundi ${ }^{3}$, Karola Dillenburger ${ }^{4}$, Nicola \\ Herbertson $^{5}$, Beth Charlesworth ${ }^{6}$, Lizbeth Goodman . \\ 1 Corresponding author University College Dublin, yurgos.politis@ucd.ie \\ 2,3,7 University College Dublin, \{nigel.robb, anita.yakkundi, lizbeth.goodman\}@ucd.ie \\ ${ }^{4}$ Queens University Belfast, k.dillenburger@qub.ac.uk \\ ${ }^{5} \mathrm{Hao2}$,nikki@hao2.eu \\ ${ }^{6}$ Autus, beth@autus.org.uk
}

\begin{abstract}
Games and virtual worlds have many potential benefits for people with intellectual disabilities (ID) and autism spectrum disorder (ASD), in terms of training, education, and rehabilitation. However, because this population presents a wide range of specific needs and abilities, it can be difficult to design games which are engaging and present optimum levels of challenge to players. By including individuals with ID and ASD in the design phase we can help meet their specific needs and preferences by personalizing an intervention through the exploration of experimental techniques, methods and assistive technologies. By embracing the Responsible Research and Innovation approach, we bring science and society closer together to shape the world for future generations. A number of approaches for achieving such inclusion have been described, such as User Sensitive Inclusive Design, Universal Design, and Design for All. Here we discuss three specific examples of the design of games and virtual worlds for people with ID/ASD and illustrate how they attempt to meet their needs. Namely 1) a blended approach of computerised program and applied behaviour analysis for reading skills 2 ) immersive gameplay for employment and transferable skills training and 3) virtual reality training to enhance communication skills.
\end{abstract}

Keywords: Assistive technology, Serious Games, Virtual Worlds, Intellectual Disabilities, Autism Spectrum Disorders.

\section{Introduction}

Autism spectrum disorder (ASD) is a neurodevelopmental disability covering a wide range of abilities and complexities [1]. The individuals experience varying levels of difficulties in communication, social, sensory regulation skills and engage in repetitive behaviours. ASD can also be accompanied by intellectual disability (ID), impacting negatively on learning and academic outcomes and other life skills. Most learners with ASD have decreased attention towards stimuli presented, especially if they are not from a special interest category, and struggle to learn with conventional methods, thus requiring teaching with a special set of methods and tools.

When designing software for individuals with ASD and ID, it is becoming increasingly common for designers to involve people with disabilities in the design process [2] [3]. This idea has its roots in user-centred design (UCD, also sometimes called human-centred design). UCD is a concept from mainstream design (i.e. it is not just, or even primarily, concerned with the design of software for people with disabilities), which is well-established in the field of software design, and an international standard for UCD has been developed [4]. According to this standard, UCD aims to furnish designers with an explicit understanding of the end user, in terms of their specific needs, and how and in what context they will use the software or product. It typically involves user evaluation of prototypes, 
which are refined iteratively based on user feedback. Importantly, the main aim of UCD is to produce "usable and useful software" [4].

However, an additional motivation for involving users in a design process is made explicit in the participatory design (PD) practices which emerged as part of the Scandinavian workplace democracy movement [5]. PD focuses on the process as well as the product, and aims at developing a design experience in which technology developers and users meet as equals, to promote reciprocal relationships, mutual learning, and empowerment of users [5].

Involving users with disabilities in the design of software should address both these motivations [3]. However, rather than a single, unified design approach, research on the involvement of people with disabilities in design processes presents a wide range of practices, frameworks, and theories. For our purposes, it will suffice to pick out three important aspects of this broad body of work.

Firstly, specific needs of people with ID and ASD may necessitate the development of novel techniques, and of novel relationships between the collaborators, to facilitate collaboration. Thus, standardised approaches to UCD may need to be adapted to be appropriate for people with ID and ASD [3].

Secondly, as with PD, the motivation is not solely to increase the usability of the software being designed. It is often a priority that co-design represents a model of design that promotes a range of benefits for the individuals involved, and for society. As such, research on co-design involving people with disabilities often reports positive outcomes for the participants, including a sense of empowerment, enjoyment, increased confidence, and improved social skills [2].

Finally, this approach to design is aligned with strategic policies. For example, the Responsible Research and Innovation (RRI) approach advocated under the European Union Framework Programme for Research and Innovation Horizon 2020 urges all those involved in a research and innovation process to work collaboratively "to better align both the process and its outcomes with the values, needs and expectations of society" [6]. Such RRI principles are also advocated by several national research councils [7].

Serious games and virtual worlds present excellent opportunities to deliver education and skills training to people with ASD and ID in a way that is particularly suitable for this population [8]. In line with the principles of RRI, a growing body of research is demonstrating the range of ways in which people with ASD and ID can be involved in the design of games and virtual worlds: Malinverni et al. [9] and Benton et al. [10] describe design methods for involving children with ASD in game design, while Robb et al. [11] describe a modified UCD approach to accommodate the preferences of children with Prader-Willi syndrome in the design of a cognitive training game.

In this paper, we add to this literature by presenting three examples of people with ID and ASD being involved in the design of games and virtual worlds in novel ways:

In Section 2, we discuss how applied behavior analysis may be applied to the development of a serious game to improve reading skills in people with ASD and ID.

Section 3 then discusses two further projects; in each project, people with ASD and/or ID are involved in the development process:

Section 3.1 discusses Hao2.eu, a social firm, with a development team consisting of $80 \%$ of people with ASD and/or ID which develops virtual worlds to improve socialization skills. Hao2 delivers courses which can be customized by the participants to meet their learning needs

Section 3.2 focuses on Virtual Learning for people with ASD (VL4ASD), a project which aims to improve communication skills. The 7-week training will be delivered through a multiple baseline design

\section{Game design addressing reading skills for people with ASD and ID}

Interventions and teaching programmes developed using Applied Behaviour Analysis (ABA) are successful, evidence-based and empirically validated and have demonstrated success in achieving educational outcomes in areas where the traditional methods are not as effective [12]. ABA focuses on individually-tailored teaching, using novel creative methods of structuring education process to enhance socially relevant or academic behaviour. Many of these features are shared with the design of video games. ABA can thus provide the theoretical and practical foundation for the design of educational games by utilising the motivational aspects of entertainment games.

Engagement in learning should encompass concentration, interest, and enjoyment, where skills, progress and perceived challenges are continuously assessed and the interventions adjusted 
accordingly to provide a user led curriculum. Single subject research designs and the interventions are user led as well as user adapted [13].

Commonly, students with ASD learn how to effectively use simple and explicit rules and these form the elements of game design. The scientific discipline of applied behaviour analysis has long recognised the importance of individualised teaching methods [14] that have proved to be highly effective for individuals on the autism spectrum [15]. Major strategies that define an intervention program using ABA [16] and form the basis of serious game design include, defining and measuring behaviour, recording and analysing behaviour, presenting corrective feedback and dynamically adapting to student performance.

ABA programmes use a wide variety of methods, including precision teaching, direct instructions, and individualised teaching, Usually, the passing or mastery criterion for a target is $\sim 90 \%$ unlike $\sim 40 \%$ in the conventional educational setting. ABA programmes are highly successful in a range of settings, educational levels, type of targets, learner populations [17-19] and have been highly successful in the special education and autism spectrum learners [20][21]. Yet, these concepts have not been adopted in the mainstream education for many reasons [22], including high level training, planning and preparation required from the educators [23][24].

Drawing parallels between ABA interventions and serious game elements will inform designers and encourage them to incorporate the behaviour analytical techniques and strategies to create usercentred serious games. In Section 2.1, we present specific examples of how ABA principles are demonstrated in a serious game designed to improve reading skills.

\subsection{User-centered game design for reading skills: examples of ABA principles in practice}

Reading is an important skill, impacting on all areas of life. Reading skill acquisition for individuals with ASD can be difficult. Reading interventions using ABA based methods, such as direct instructions have shown efficacy in imparting reading skills to students with ASD [25][26].

On the other hand, children with ASD often enjoy video games that have proved intrinsically motivational. Therefore, it would make sense to include serious game design in reading instruction to allow this skill to be achieved and generalised, i.e. used in all contexts of their lives. This would have a significant positive impact on their lives as evidenced by the Alpha Reading program for autism that includes game elements of short-term goals, increasing levels of difficulty and some provision of choice in sentence construction [27] and has demonstrated good transfer of learned skills.

Headsprout Early Reading (HER, also known as Mimiosprout), a computerised reading programme, is another example, which has demonstrated proficiency for slow readers and students with autism [28][29]. To make it suitable for learners with ASD and moderate to severe ID, we designed a blended model of serious game using therapist/teacher aided support and HER. The additional inter-person activities during blended model interventions will provide valuable scaffolding for increasing generalisation of learning as recommended [30].

This blended user-centered design applying behaviour analysis for shaping of individual learning of HER lessons fulfils the general guidelines of the evidence based game design. It has an interactive and animated story line, because an immersive storyline is required for contextualising the learning goals as well as maximising learning. HER has 80 lessons, made of stories that use animated characters with whom the students can identify with and develop empathy. Each lesson has segments that provide a short line for the student to engage in while learning the reading elements of phonemes, phonics, vocabulary and fluency

This approach is goal directed and the intervention is designed to achieve precise and incremental goals before moving on to next stage. The immediate goal is to complete a timeframe and/or a segment within a lesson, the intermediate goal is to complete a lesson, and the end goal is to achieve various reading milestones embedded in the lessons. Goals directed around targeted skills of phonemes, phonics, vocabulary, fluency followed by comprehension.

It involves both extrinsic and intrinsic rewards in points and pleasure. The topic of the serious game, i.e. reading comprehension, is embedded within the HER episodes; each episode is teaching the learner reading skill components and reinforces the learnt skills along the 80 episodes. The rewards or stars earned during the lessons are increasing the learning behaviour thus providing intrinsic motivation that leads to generalisation of reading skills to books. For a complex learner having low level of sustained attention, use of ABA to provide immediate extrinsic motivation increases the level of sustained attention to use the HER. 
HER has auditory as well as visual feedback for each activity. There are also additional certificates and social praises that the teacher can provide to build on the feedback and rewards., in addition to the star and robot builder, which are additional motivators and these are acquired on a cumulative basis.

ABA methods offer a provision of choice in terms of reinforcements and activities. Learners are continually assessed for their reinforcements using preference assessments which are provided as extrinsic motivators for learners with complex needs. HER offers a choice of generalising the reading activity using e-books or in-print books supporting each session.

HER offers individualised training due to the fact it has inbuilt prompts that are adjusted in response to the user's response to each activity within the reading game/session. The number of trials is also adjusted depending on the correct responses made. Additional support provided by the behaviour analyst/therapist to ensure correct leaning is taking place provides a positive learning strategy. A baseline measured for each learner and an HER placement assessment gives an individualised starting point.

This approach can have progressive increase in levels of difficulty, which is required to provide achievable challenges addressing the goal and target lists as the session go from 1 to 80 . It doesn't require a sophisticated device, just the use of a touch screen device such as iPad or tablet that can run the kids a-z app. For higher functioning children, a computer with mouse is used. These devices are further complimented by either e-books or paperback books. Complex learners will be assisted by teachers and therapists using pictures and supporting material delivered by applying behaviour analytical strategies.

Lastly, HER can be easily used in the school environment, because it encompasses the guidelines set out by National reading panel (2000) and embraces very strongly the 'no child left behind' act [31-33], wherein, all students including those with disability are expected to gain reading proficiency.

This model of UCD offers a novel co-design approach with ABA and the computer program (HER), where the continual analysis of the learning behaviour allows the intervention to be tailored to the user's pace and skills (Fig 1).

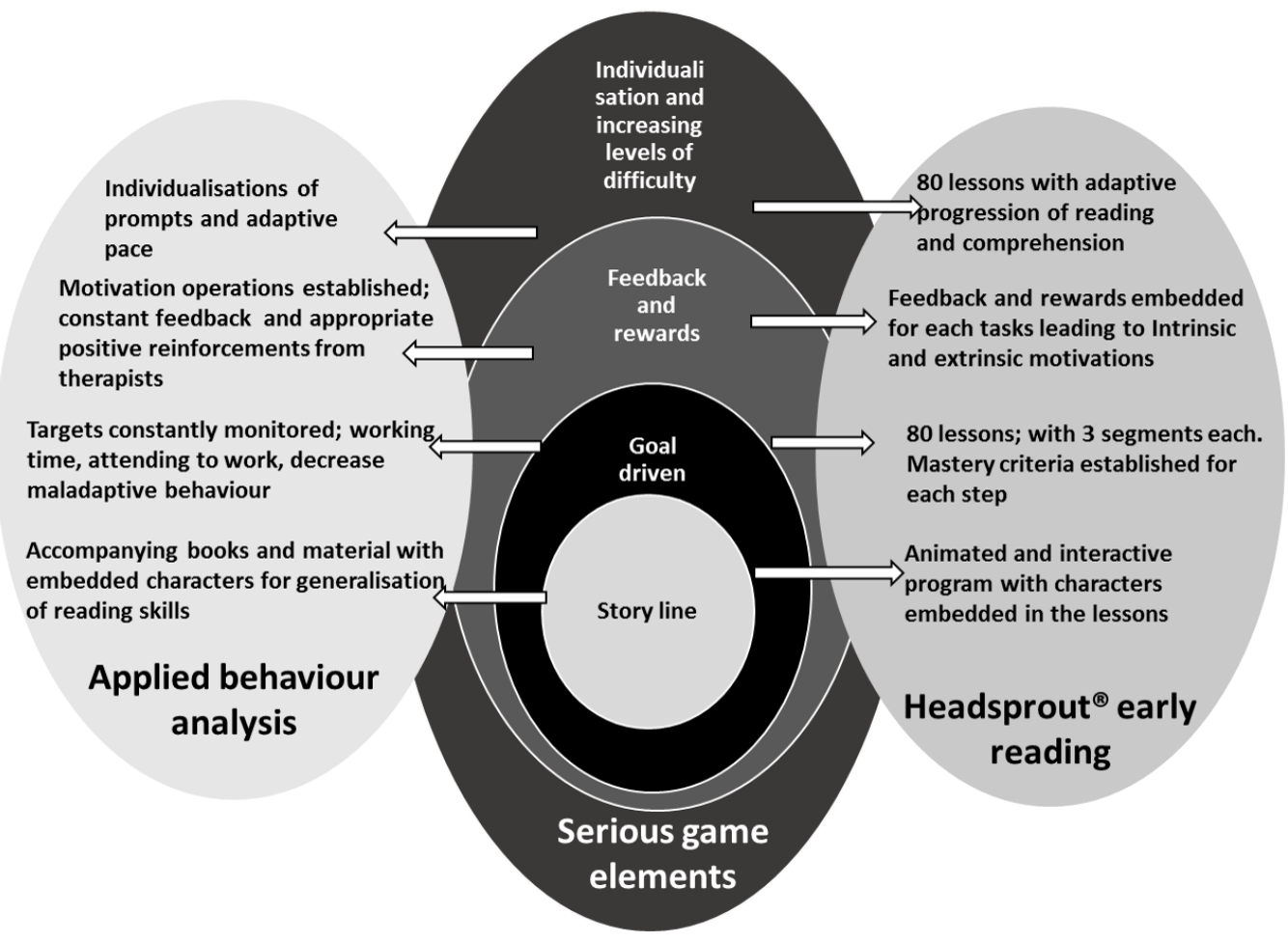

Figure 1: Inclusive program for comprehension and reading using a blended approach of applied behaviour analysis and Headsprout ${ }^{\circledR}$ early reading program with touchscreen gadgets 


\section{Virtual Reality training for people with ASD/ID}

The term Virtual Reality has been around since the 1960s; it faded away and came back to the fore a few times due to difficulties implementing the technology and high associated cost with the hardware and software development. Virtual Reality has made a big comeback in recent years due to technological advances that have made it more affordable to the public. The Virtual World environments created, involve people (as avatars) in a space that doesn't exist and yet that simulates the real world, "places where the imaginary meets the real" [34]. A more comprehensive definition is that a Virtual World is "a synchronous, persistent network of people, represented as avatars, facilitated by networked computers" [35].

A Virtual World can either be a non-immersive (on a computer/laptop/tablet screen) or immersive (VR glasses, Head Mounted Displays) 3D space delivered over the Internet to a PC. The characters are represented by avatars and they can talk to each other by voice or text chat, in public or in private. Virtual Worlds are bespoke environments that support training in a safe environment avoiding potential real dangers and where one can embed training and learning exercises in order to achieve goals and have thus found application in an educational context.

Studies have shown that a Virtual 3D environment can stimulate users' interactivity [36] and motivation [37][38]. It affords opportunities for social interaction, especially in the classroom by making conversations easy, structured and inclusive, through for example the text-chat systems [39]. Virtual Worlds can offer users a sense of co-presence and realism [40][41] and provide an increased sense of control, allowing participants to have more engaging in-world experiences [42]. Moreover, Virtual Worlds can improve students' knowledge, their enjoyment and interest in the learning process, if they are structured correctly, just like game-based learning does. [43].

The next two sections of this article will showcase examples of application of the Virtual Reality technology as part of training of young adults with ASD/ID. The first example addresses employability and transferable skills training whereas the second example addresses communication skills, more specifically the art of conversation.

\subsection{Immersive Gameplay for Employability and Transferable Skills Training}

A recent National Autistic Society survey in the UK, on autism and employment revealed that even though $77 \%$ of respondents want to work, only $16 \%$ of adults with autism are in full-time paid work and only $32 \%$ are in any kind of employment [44]. This disheartening news comes despite the efforts of several high-profile employers, among them Microsoft, SAP and Vodafone [45] to recruit people with autism for the skills they can bring to the workplace. However, research shows that individuals with ASD may have enhanced skills that are important for successful employment in certain areas [46], such as enhanced perceptual capacities [47], the ability to make more rational decisions by being less influenced by emotions [48], and better performance on measures of fluid intelligence [49].

The reasons for this discrepancy are related to both internal and external factors [50]. The former category incorporates challenges related to social communication difficulties that individuals with ASD may exhibit, including social difficulties presented in job interviews and comorbidity (e.g. a secondary diagnosis of intellectual disability or mental/emotional disorders is associated with less likelihood of employment) [51]. External factors are related to, for example, a lack of awareness and understanding by employers [52] and a lack of vocational services for people with ASD [50].

The aim of Hao2.eu is to teach life skills to people with autism through immersive online gaming technology. The choice to socialise online is a decision many people with autism make, and there is a need to offer them more options to interact online because many people with autism are more comfortable with such interaction [53]. Autistic people have a strong preference for online interaction, which may be due to the familiar structures of online communication, the ability to choose conversation topics and/or the option of responding in one's own time [54].

However, this kind of online interaction should only be a starting point, which is one of the recommendations by Hastwell et al. [53] that $\mathrm{HaO} 2$ and its charitable arm Autus espouse. Courses are designed to use the safe virtual environment to help people with autism reach beyond their comfort zone. For instance, participants may start off communicating by text in the virtual world, but move on to voice as they gain confidence. Likewise, if a participant finds a particular environment difficult or overwhelming, a simulation can be built to practise until it becomes familiar.

As well as delivering its courses in a way that echoes the social environments people with autism often choose, Hao2 also gives individual learners considerable say over their course content. Participants evaluate their strengths and weaknesses and create personal projects to address the 
weaknesses and build on the strengths. Any user can contribute his/her personal touch to the space by creating things that enhance the environment, from introductory training modules to evaluation tools. Our learners engage in peer mentoring and can gain work experience training others to use the virtual world and/or building customised 3D environments for local authorities and other partner organisations (such as JobcentrePlus Swindon, now the proud owner of an exact digital replica of its premises for a Journey to Employment project). In that sense, the virtual environment can adapt infinitely to suit individual differences because the individual users build it.

This emphasis on handing decision-making power to people with autism, involving hard-to-reach stakeholders at every step of the process, empowered by an innovative use of technology with which they are already familiar and better connected with society in general, especially employers, has led Hao2.eu and Autus being shortlisted for the inaugural European Foundations Awards for Responsible Research and Innovation (EFARRI) [55].

Most importantly, this new approach to developing autistic people's employability skills is proving effective, since 2015-6 Winchester's Jobcentreplus Work Programme (2015-16) has so far $40 \%$ work-related outcomes for people receiving Employment and Support Allowance (financial support for ill or disabled people unable to work and personalised help to find work), compared to $12.5 \%$ national average (new claimants get a job outcome within two years) [56]. The first cohort of learners in our pilot scheme for the Department for Work and Pensions' (DWP) Journey to Employment at Swindon Jobcentreplus had 20\% employment outcomes by week 11 of a 12 -week course.

Moreover, Hao2 is also currently trialling an e-mentoring scheme to match people with autism interested in working in technology with IT professionals who can share their expert knowledge of how to get hired in technology, based on connections in the IT industry as well as Hao2.eu's learners' established influence in technology. Initial results are showing that with mentors' help, participants are building portfolios, improving interview techniques, finding freelance work and generating revenue developing their own software. In keeping with our user-led credo, participants are also sharing tips online via our peer support job club to help others find work.

We therefore believe that our success in helping people with autism develop their talents and find work stems from the core RRI principles [57] especially public engagement (involving all stakeholders, particularly people with autism whose voices are too often not heard) and open access (empowering participants to share best practice and support each other). If the aim of autism research is to improve quality of life, then outcomes can be improved by understanding and helping participants progress towards their idea of a good quality of life. We are keen to participate in more research to develop a broader evidence base for the scale and scope of the improvements RRI approaches can bring to autism research and the lives of its beneficiaries.

\subsection{Virtual Learning for people with ASD (VLAASD) - communication skills training}

Extensive research has been carried out about the affordances and benefits of the use of Virtual Reality to the general population. However, a recent systematic review of immersive virtual reality technologies [58] showed that very little research has been carried out with people with disabilities and more particularly people with ID. That is the type of population that could benefit most from VR, since people with Intellectual Disabilities can potentially benefit from the fact that "learning in a virtual environment that reproduces the real one can minimize the problems related to learning transfer" (p.139) [58]. Learning transfer doesn't seem to be a problem in the studies Standen and Brown [59] examined, however there is a need for extensive studies to establish whether the transfer is easier with a VR approach compared to traditional ones.

The VL4ASD project, will investigate whether using a non-immersive Virtual World for social skills training can be beneficial for the people with ASD and/or Intellectual Disabilities. A secondary aim is to establish the best way to measure the effectiveness of the aforementioned training.

The VL4ASD project's aim is to create training material on communication skills using a Virtual Reality environment. This is a specific example of training currently being implemented on a platform co-designed by people with ASD/ID, and they have been and will be consulted at all phases of the project (i.e. inception, development and piloting), so they will be co-designers. The material will be personalized according to the needs and preferences of each participant based on a review of their Individual Education Plan and in consultation with the participants and other relevant stakeholders. This training, it is hoped, would help the target population (people with ASD and/or IDs) in their transition from education and/or training to independent living. 
The study will measure elements of communication skills including but not limited to starting a conversation, picking appropriate topics for discussion, sustaining a conversation, knowing when to end a conversation, maintaining eye contact, respecting other people's personal space etc. Since the study aims at developing an intervention that is customized for each participant, there is going to be an in depth focus on specific cases. The developed learning scenarios will be adapted and modified to each student's unique circumstances and therefore the sample will be kept rather small, three participants from the USA and three from Ireland that are young adults (15-year olds to mid-twenties)

The nature of the study - focusing on individuals rather than groups and measuring the effect of the intervention on an individual basis and not concerned with the generalizability of the findings lends itself to a single case experimental design, and more specifically a multiple baseline design.

The intervention will be a social scenario of having a conversation with a friend. The participants will initially interact with the researcher physically (stage 1) and then virtually (stage 2) to determine whether virtual reality on itself has a positive impact. Stage 3 will involve instruction (PowerPoint presentations, videos, and exercises with a non-playable character) in the virtual environment followed by the same interaction to determine whether instruction in virtual reality is beneficial. Stage 4 will be a repeat of stage 1 to determine whether the participants could bring any skill acquisition from the virtual to the real world. The assessment will be carried out with the following measures:

1. Observations will be rated either on a Likert scale (Poor/Fair/Good/Excellent) or YES/NO, by 3-4 reviewers.

2. Specialists that know the participants' history (e.g. Disability Network Team members in the US) will fill in the Perceived Empathic Self-Efficacy Scale (5 items), the Perceived Social Self-Efficacy Scale (6 items) and the Generalized Anxiety Disorder Scale (7 items). The measures will be filled in pre and post intervention.

3. Video will be used to identify appropriate non-verbal communication (the consent/assent forms will include a specific section on usage of video)

This assessment will determine whether the intervention had any impact on each participant's communication skills.

The technological aspect of the project (an assistive technology), is a Virtual World that is a first iteration of the Hive-RD construct powered 3DNovations platform, at an early alpha stage. It is developed with and for people with autism and intellectual disabilities. This is the first instance of Hive-RD being used as a tool for Responsible Research and Innovation (RRI) [57] to help people with autism and IDs. The OpenSim platform [60] was deemed more appropriate for the creation of training material, due to the fact that it is free and more user-friendly. However, the Unity platform will be utilised for the delivery of the intervention in the Virtual World because it is more customizable.

The intervention is currently being developed using three simple stages; the pedagogical (training material - presentations, videos and non-playable character) and technical (the virtual world space and social scenarios) designs are being developed [61]. The Virtual World has gone through several iterations through initial testing by the developers, followed by extensive sessions with testers most of whom have ASD, in order to address accessibility and usability issues. It is now entering the piloting phase with people with ASD and/or IDs, followed by revision and improvement of the products based on the feedback. The last two phases may be repeated more than once if it is deemed necessary.

When the participants are chosen, the researcher will review their Individual Education Plans (IEPs) and then have a consultation with them and their parents (maybe even professionals that know them and/or have worked with them closely) in order to determine what their goals would be. The researcher would then take them through the Virtual World environment and the training scenarios and ask for their feedback. It is hoped that through this process they will feel co-ownership of the process and end product and participate with enthusiasm. Upon completion of the piloting/testing phase of the project (estimated in late September 2017), a 7-week intervention will be delivered and the training outcomes will determine the future direction of the research. This could include exploring the delivery of the training through immersive Virtual Reality or Augmented Reality.

\section{Conclusions}

In this paper we have presented three examples of projects in which people with ASD and ID are involved in the design of serious games and virtual worlds. The projects demonstrate two novel 
approaches to this involvement, both of which highlight important avenues for future work in this field.

Firstly - in Section 2 - we have described how ABA can provide a framework for the usercentred design of serious games for people with disabilities. Importantly, this provides an evidencebased technique which can underpin a user-centred design process. Future work should investigate the effectiveness of serious games developed using such an ABA-based framework as interventions for people with ASD.

Secondly, we have described in detail two examples of a user-led approach to the design of virtual worlds, and shown how a virtual world developed in this way is effective in providing employment related outcomes for people with ASD.

The three projects described in this paper each aim to improve different skills in people with ASD and/or ID: reading skills (Section 2), socialization skills (Section 3.1), and communication skills (Section 3.2).

As noted in our introduction, there are two main motivations for involving users with disabilities in the design of software in this way: ensuring the usability and usefulness of the software developed; and potentially delivering a range of wider social and individual benefits. Limited research has considered the latter in detail, with findings often reported in terms of researcher observations [2]. We therefore conclude by recommending that future research on user-centred and user-led design involving people with disabilities seeks to measure and report on the potential wider benefits for participants, for example, in terms of feelings of ownership, empowerment, and social inclusion.

\section{Acknowledgement}

This research was supported by funding from the charity RESPECT and the People Programme (Marie Curie Actions) of the European Union's Seventh Framework Programme (FP7/2007-2013) under REA grant agreement no. PCOFUND-GA-2013-608728'

\section{References}

[1] American Psychiatric Association - APA, Diagnostic and statistical manual of mental disorders (5th ed.), Washington, DC: Author, 2013

[2] Benton, L., Johnson, H., Widening participation in technology design: A review of the involvement of children with special educational needs and disabilities, International Journal of Child-Computer Interaction, Vol. 3, pp. 23-40, 2015. https://doi.org/10.1016/j.ijcci.2015.07.001

[3] Newell, A. F., Gregor, P., Morgan, M., Pullin, G., Macaulay, C., User-sensitive inclusive design. Universal Access in the Information Society, Vol. 10, Nr. 3, pp. 235-243, 2011 https://doi.org/10.1007/s10209-010-0203-y

[4] International Organization for Standardization (ISO), "ISO 9241-210:2010: Ergonomics of human-system interaction - Part 210: Human-centred design for interactive systems", Geneva Switzerland: ISO, 2010

[5] Muller, M. J., Druin, A., "Participatory Design: The third space in HCI", In J. Jacko (Ed.), The Human-Computer Interaction Handbook $-3^{\text {rd }}$ Edition, pp. 273-291. New York: Taylor \& Francis, 2011.

[6] "Responsible Research \& Innovation", (2017, January 18). Retrieved from https://ec.europa.eu/programmes/horizon2020/en/h2020-section/responsible-researchinnovation

[7] Von Schomberg, R., “A vision of responsible research and innovation”, In R. Owen, M. Heintz and J. Bessant (Eds), Responsible innovation: Managing the responsible emergence of science and innovation in society, pp. 51-74. London: John Wiley, 2013 https://doi.org/10.1002/9781118551424.ch3

[8] Durkin, K., Videogames and young people with developmental disorders, Review of General Psychology, Vol. 14, Nr. 2, pp. 122-140, 2010. https://doi.org/10.1037/a0019438

[9] Malinverni, L., Mora-Guiard, J., Padillo, V., Valero, L., Hervás, A., Pares, N., An inclusive design approach for developing video games for children with Autism Spectrum Disorder, Computers in Human Behavior, (In press), 2016. 
[10] Benton, L., Johnson, H., Brosnan, M., Ashwin, E., Grawemeyer, B., "IDEAS: an interface design experience for the autistic spectrum". In CHI'll Extended Abstracts on Human Factors in Computing Systems (pp. 1759-1764), ACM, 2011 https://doi.org/10.1145/1979742.1979841

[11] Robb, N., Waller, A., Woodcock, K. A. (2015). "The development of TASTER, a cognitive training game using human-centred design, tailored for children with global and specific cognitive impairments". In proceedings of Virtual worlds and games for serious applications, Skövde, Sweden, 2015. https://doi.org/10.1109/VS-GAMES.2015.7295788

[12] Linenhall, C., Kirman, B., Lawson, S., Chan, G.G.," Practical Appropriate Empirically-Validated Guidelines for Designing Educational Games", CHI'11 Proceedings of the SIGCHI Conference on Human Factors in Computing Systems, pp. 1979-1988, 2012

[13] Keenan, M., Dillenburger, K., When all you have is a hammer ...: RCTs and hegemony in science, Research in Autism Spectrum Disorders, Vol. 5, Nr. 1, pp. 1-13, 2011. http://doi.org/10.1016/j.rasd.2010.02.003

[14] Green, G., Brennan, L. C., Fein, D., Intensive behavioral treatment for a toddler at high risk for autism, Behavior Modification, Vol. 26, Nr. 1, pp. 69-102, 2002. https://doi.org/10.1177/0145445502026001005

[15] Peters-Scheffer, N., Didden, R., Korzilius, H., Sturmey, P., A meta-analytic study on the effectiveness of comprehensive ABA-based early intervention programs for children with Autism Spectrum Disorders, Research in Autism Spectrum Disorders, Vol. 5, Nr. 1, pp. 60-69, 2011. http://doi.org/10.1016/j.rasd.2010.03.011

[16] Cooper, J. O., Heron, T. E., Heward, W. L., Applied Behavior Analysis, USA: Pearson Prentice Hall, 2007

[17] Dillenburger, K., The emperor's new clothes: Eclecticism in autism treatment, Research in Autism Spectrum Disorders, Vol. 5, Nr. 3, pp. 1119-1128, 2011. http://doi.org/10.1016/j.rasd.2010.12.008

[18] Dillenburger, K., Why reinvent the wheel? A behaviour analyst's reflections on pedagogy for inclusion for students with intellectual and developmental disability, Journal of Intellectual and Developmental Disability, Vol. 37, Nr. 2, pp. 169-180, 2012. http://doi.org/10.3109/13668250.2012.685705

[19] Dillenburger, K., Keenan, M., Doherty, A., Byrne, T., Gallagher, S., ABA-Based Programs for Children Diagnosed With Autism Spectrum Disorder: Parental and Professional Experiences at School and at Home, Child \& Family Behavior Therapy, Vol. 34, pp. 111-129, 2012. http://doi.org/10.1080/07317107.2012.684645

[20] Grindle, C. F., Hastings, R. P., Saville, M., Hughes, J. C., Huxley, K., Kovshoff, H., ... Remington, B., Outcomes of a behavioral education model for children with autism in a mainstream school setting, Behavior Modification, Vol. 36, Nr. 3, pp. 298-319, 2012. http://doi.org/10.1177/0145445512441199

[21] Horner, R. H., Carr, E. G., Halle, J., McGee, G., Odom, S., Wolery, M., The use of single-subject research to identify evidence-based practice in special education, Exceptional Children, Vol. 71, Nr. 2, pp. 165-179, 2005. http://doi.org/10.1177/001440290507100203

[22] Dillenburger, K., McKerr, L., Jordan, J.A., Lost in translation: Public policies, evidence-based practice, and Autism Spectrum Disorder, International Journal of Disability, Development and Education, Vol. 61, Nr. 2, pp. 134-151, 2014. http://doi.org/10.1080/1034912X.2014.905059

[23] Dillenburger, K., "Staff training", In J. Matson (Ed.), Handbook of Autism Treatments, US: Springer, 2016.

[24] Fennell, B., Dillenburger, K., Applied behaviour analysis: What do teachers of students with autism spectrum disorder know, International Journal of Educational Research, (In Press), 2016. Retrieved from http://www.sciencedirect.com/science/article/pii/S088303551630057X https://doi.org/10.1016/j.ijer.2016.06.012

[25] Allor, J.H., Champlin, T.M., Gifford, D.B. \& Mathes, P.G., Methods for Increasing the Intensity of Reading Instruction for Students with Intellectual Disabilities, Education and Training in Autism and Developmental Disabilities, Vol. 45, Nr. 4, pp. 500-511, 2010

[26] Allor, J.H., Mathes, P.G., Roberts, J.K., Cheatham, J.P. \& Al Otaiba, S., Is Scientifically Based Reading Instruction Effective for Students With Below-Average IQs? Exceptional children, Vol. 80, Nr. 3, pp. 287-306, 2014 https://doi.org/10.1177/0014402914522208

[27] Heimann, M., Nelson, K.E., Tjus, T., Gillberg, C., Journal of Autism and Developmental Disorders, Vol. 25, pp. 459-480, 1995. doi:10.1007/BF02178294

[28] Grindle, C.F., Hughes, J.C., Saville, M., Huxley, K. \& Hastings, R.P., Teaching Early Reading Skills to Children with Autism Using Mimiosprout Early Reading, Behavioral Interventions, Vol. 28, pp. 203-224, 2013. https://doi.org/10.1002/bin.1364 
[29] Plavnick, J.B., Marchand-martella, N.E., Martella, R.C., Thompson, J.L. \& Wood, A.L., A Review of Explicit and Systematic Scripted Instructional Programs for Students with Autism Spectrum Disorder, Review Journal of Autism and Developmental Disorders, Vol. 2, Nr. 1, pp. 55-66, 2015. https://doi.org/10.1007/s40489-014-0036-3

[30] Wouters, P., van Oostendorp, H., A meta-analytic review of the role of instructional support in game-based learning, Computers and Education, Vol. 60, Nr. 1, pp. 412-425, 2013 https://doi.org/10.1016/j.compedu.2012.07.018

[31] No Child Left Behind Act of 2001, (2002) 20 U. S. C. 706301 et seq.

[32] National Reading Panel (U.S.), (2000). Report of the National Reading Panel - Teaching children to read: an evidence-based assessment of the scientific research literature on reading and its implications for reading instruction (reports of the subgroups), Washington, D.C.: National Institute of Child Health and Human Development, National Institutes of Health, 2000.

[33] Alberto, P.A., Heflin, J., Literacy: Introduction to the Special Series, Focus on Autism and Other Developmental Disabilities, Vol. 22, Nr. 4, pp. 204-205, 2007. https://doi.org/10.1177/10883576070220040201

[34] Bartle, R. A., Designing Virtual Worlds, US: New Riders Publishing, 2004

[35] Bell, M. W., Toward a definition of "virtual worlds", Journal of Virtual Worlds Research, Vol. 1, Nr. 1, pp. 1-5, 2008.

[36] Roussou, M., Learning by doing and learning through play: an exploration of interactivity in virtual environments for children, Computers in Entertainment, Vol. 2, Nr. 1, pp. 10-10, 2004. https://doi.org/10.1145/973801.973818

[37] Garris, R., Ahlers, R., Driskell, J. E., Games, motivation, and learning: A research and practice model, Simulation \& gaming, Vol. 33, Nr. 4, pp. 441-467, 2002. https://doi.org/10.1177/1046878102238607

[38] Ott, M., Tavella, M., A contribution to the understanding of what makes young students genuinely engaged in computer-based learning tasks, Procedia-Social and Behavioral Sciences, Vol. 1, Nr. 1, pp. 184-188, 2009. https://doi.org/10.1016/j.sbspro.2009.01.034

[39] Newbutt, N., Immersive Learning Environments: The State of the Art - Learnovate Project Report, Ireland: Trinity College Dublin, 2013.

[40] Childs, M., Learners' Experience of Presence in Virtual Worlds, Thesis (PhD), University of Warwick, 2010.

[41] Yee, N., Bailenson, J.N., Ducheneaut, N., The Proteus effect: Implications of transformed digital self-representation on online and offline behaviour, Communication Research, Vol. 36, Nr. 2, pp. 285-312, 2009. https://doi.org/10.1177/0093650208330254

[42] de Freitas, S., Rebolledo-Mendez, G., Liarokapis, F., Magoulas, G., Poulovassilis, A., Learning as immersive experiences: Using the four-dimensional framework for designing and evaluating immersive learning experiences in a virtual world, British Journal of Educational Technology, Vol. 41, Nr. 1, pp. 69-85, 2010. https://doi.org/10.1111/j.1467-8535.2009.01024.X

[43] Papastergiou, M., Digital Game-Based Learning in high school Computer Science education: Impact on educational effectiveness and student motivation, Computers \& Education, Vol. 52, Nr. 1, pp. 1-12, 2009 https://doi.org/10.1016/j.compedu.2008.06.004

[44] National Autistic Society, The autism employment gap, 2016 Retrieved from http://www.autism.org.uk/get-involved/tmi/employment.aspx

[45] Remington, A., Why employing autistic people makes good business sense, April 2015, Retrieved from http://theconversation.com/why-employing-autistic-people-makes-goodbusiness-sense-39948

[46] Mottron, L., Changing perceptions: The power of autism, Nature, Vol. 479, Nr. 7371, pp. 33-35, 2011 https://doi.org/10.1038/479033a

[47] Remington, A., Swettenham, J., Campbell, R., Coleman, M., Selective attention and perceptual load in autism spectrum disorder, Psychological Science, Vol. 20, Nr. 11, pp. 1388-1393, 2009. https://doi.org/10.1111/j.1467-9280.2009.02454.X

[48] De Martino, B., Harrison, N. A., Knafo, S., Bird, G., \& Dolan, R. J. (2008). Explaining enhanced logical consistency during decision making in autism, Journal of Neuroscience, Vol. 28, Nr. 42, pp. 10746-10750. https://doi.org/10.1523/JNEUROSCI.2895-08.2008

[49] Dawson, M., Soulières, I., Gernsbacher, M. A., Mottron, L., The level and nature of autistic intelligence, Psychological science, Vol. 18, Nr. 8, pp. 657-662, 2007. https://doi.org/10.1111/j.1467-9280.2007.01954.x

[50] Chen, J. L., Leader, G., Sung, C., Leahy, M., Trends in employment for individuals with autism spectrum disorder: a review of the research literature, Review Journal of Autism and 
Developmental Disorders, Vol. 2, Nr 2, pp. 115-127, 2015. https://doi.org/10.1007/s40489-0140041-6

[51] Schaller, J., Yang, N. K., Competitive employment for people with autism: correlates of successful closure in competitive and supported employment, Rehabilitation Counseling Bulletin, Vol. 49, Nr. 1, pp. 4-16, 2005 https://doi.org/10.1177/00343552050490010201

[52] López, B., Keenan, L., Barriers to employment in autism: future challenges to implementing the Adult Autism Strategy. Autism Research Network, 2014

[53] Hastwell, J., Harding, J., Martin, N., Baron-Cohen, S., Asperger Syndrome Student Project, 2009-12: Final Project Report, University of Cambridge, June 2013

[54] Johnson, J., Exploring the Social Experiences of Adults on the Autistic Spectrum: Views on Friendships, Dating and Partnerships, 2014. https://curve.carleton.ca/system/files/theses/31686.pdf

[55] 3DNovations - European Foundations Award for Responsible Research \& Innovation (n.d.). http://efarri.eu/finalist/3dnovations/ Accessed 6/2/2017.

[56] Bivand, P., Melville, D., Work Programme Statistics: Learning and Work Institute Analysis, Leicester UK: Learning and Work Institute, March 2016.

[57] RRI Tools (n.d.), https://www.rri-tools.eu/ Accessed 6/2/2017

[58] Freina, L., Ott, M., A Literature Review on Immersive Virtual Reality in Education: State of the Art and Perspectives, eLearning \& Software for Education, Vol. 2015, Nr. 1, pp. 133-141, 2015.

[59] Standen, P. J., Brown, D. J., Virtual reality in the rehabilitation of people with intellectual disabilities: review, Cyberpsychology and behavior, Vol. 8, Nr. 3, pp. 272-282, 2005. https://doi.org/10.1089/cpb.2005.8.272

[60] Opensimulator (Opensim) platform, http://opensimulator.org/wiki/Main_Page

[61] Reimann, P., Freebody, P., Hornibrook, M., Howard, S., Immersive learning environments, Australia: The University of Sydney, 2009 [Online] Available: http://www.ndlrn.edu.au/verve/_resources/Study_of_teachers_using_TLF_resources_2009.pdf 